two children than three. At first sight, it might appear that this diminution in the number of children will seriously curtail an important section of medical practice-obstetrics and the care of children. But the fewer the children, the more precious will they be, and though childbirth will be less common it will require more skilled assistance, hence these changes will not cause a proportionate decrease in the demands on the medical profession. The steady increase in the number of persons over sixty-five years of age, that has coinmenced already, is bound to have a very marked effect on medical practice, for the human body, though a marvellous machine, is not immune to the wear and tear of life and hence requires increasing attention in old age. One outstanding change in medical practice in the future is likely to be a rapidly increasing demand for skilled assistance to combat the minor disabilities of old age.

\section{X-Ray Equipment at the Sheffield Radium Centre}

Av event of considerable interest was the opening by H.R.H. the Duchess of York on July 5 of the new Sheffield Radium Centre. It may be mentioned that the Royal Infirmary has been a National Radium Centre for some years. A noteworthy feature of the installation is a new deep X-ray therapy set which has been supplied by the Research Department of the Metropolitan-Vickers Electrical Co., Ltd., and the installation is unique. The equipment comprises two X-ray tubes and the necessary associated apparatus, operating at 200,000 volts. The arrangement is such that it is possible to treat two patients simultaneously, but the apparatus is designed so that this is done with a minimum of complications. The Metropolitan-Vickers Electrical Company's high-voltage X-ray tube for deep therapy treatment has only been rendered possible by the production in the Company's research laboratories of a range of low vapour pressure oils for use as working fluids in condensation pumps, thus enabling the highest vacua to be attained without the use of liquid air or other cooling media. These pumps had already been applied to evacuate dismountable valves, and a considerable amount of experience had been gained on their operation under commercial service conditions. The $\mathrm{X}$-ray tubes possess two great advantages ; these are the ease with which filaments, targets, etc., can be replaced, the costly tube renewals necessary in a sealed-off apparatus being eliminated, and the fact that, once the tube has been conditioned, no great care need be taken in the application of the high voltage.

The X-ray tube itself is of a robust design, and is continuously rated at $200 \mathrm{kV}$. D.C., 10 milliamperes. Adequate safety factors are provided; for example, the external spark-over voltage is about $300 \mathrm{kV}$., while that for the internal parts is much higher. The target is at earth potential, and it thus becomes possible to cool it with water from the ordinary high-pressure mains; experimental work has shown that a power of $6 \mathrm{~kW}$. may be dissipated in $1 \mathrm{sq} . \mathrm{cm}$. of a gold target cooled in this way. The whole equipment-X-ray tube, rectifiers and pumps-is completely automatic ; in all cases, the operation of a simple press switch starts a pumping sequence which ends, if the complete vacuum system is in normal operating conditions, with the switching on of the filaments. Vacuum relays are employed to control the electrical circuits in relation to the vacuum conditions, while illuminating diagrams are arranged to show continuously the state of both vacuum and electrical eireuits.

\section{Gift of Handley Page Aeroplane to the Science Museum}

THE Handley Page aeroplane Gugnunc was presented to the Aeronautical Section of the Science Museum on July 19. On behalf of Lord Londonderry, Sir Christopher Bullock, in presenting the aeroplane, said that this machine marks a very distinct period in aviation, namely, the point at which safety in the air became one of the prime considerations as distinct from speed and carrying capacity. Mr. Handley Page's Gugnunc was built to participate in the Daniel Guggenheim International Safe Aircraft Competition held in the United States in 1929. Sir John Siddeley also presented the 150 horse-power Siddeley Mongoose air-cooled radial engine which is fitted in the Gugnunc. The aeroplane embodies the principle of the Handley Page slot which has been one of the most valuable contributions of British designers towards the security and safety of those who travel by air. The great enemy of the pilot, particularly in large machines, has been the 'stall', that is to say, there is a point at which the machine may be so far tilted backwards that it loses its power of lift and falls, sometimes uncontrollably, towards the earth. The great benefit derived from $\mathrm{Mr}$. Handley Page's slot is that it enables the machine to fly at a much lower speed than normal before this danger point is reached. In fact, even after the machine has stalled, the pilot can retain control, and he does not fall into a dangerous dive or spin, but the machine sinks on a level keel. The slot has been adopted for the very large majority of aircraft used in the Royal Air Force as well as for private and commercial aircraft. In addition, 34 other countries use the device on military and civil aircraft. The designers have not yet exhausted the possibilities of the principle which is embodied in the Handley Page slot, and the technical staff both at the Handley Page works and at the Air Ministry have for a long time been engaged on research into the various possibilities arising out of this principle. The other two full-size machines in the Section are Wilbur Wright's machine, in which the first flights were made, and Alcoek and Brown's Vimy which flew the Atlantic.

\section{Water Supplies and the Drought}

IN an article on "Water Supplies and the Drought" in the Quarterly Review of July, it is stated that the severe drought has found most urban water undertakings in a sound condition, with reasonable provision for emergencies. They should, however, thoroughly review their position in the light of recent experience, though they should be careful to avoid 